Author version: Nat. Hazards, vol.57(2); 2011; 385-393

\title{
Occurrence of soft sediment deformation at Dive Agar beach, west coast of India: possible record of the Indian Ocean tsunami (2004)
}

\author{
D. C. Meshram ${ }^{1}$, S. J. Sangode ${ }^{1,2}$, A. R. Gujar ${ }^{3}$, N. V. Ambre ${ }^{3}$ Dhongle $^{1}$, and Porate ${ }^{1}$ \\ 1. Department of Geology, University of Pune, Pune - 411007
}

2. Wadia Institute of Himalayan Geology, Dehradun 248001

3. National Institute of Oceanography, Dona Paula, Goa 403004

\section{Abstract}

Authors describe here a sequence of soft sediment deformation (SSD) structures at Dive Agar beach near Srivardhan in the west coast of India. The approx.120-cm-thick sediment package is represented by a basal undeformed sand (layer A) sharply cut by approx.30-cm-thick intermixed beach sand and terrigenous sand (layer B1) followed by complex load structures and convolutions $(8-15 \mathrm{~cm})$ within a coarse sandy layer (B2). The layer B2 is scoured by terrigenous sand (layer C1) which is capped with a silty mud layer $(\mathrm{C} 2)$. The entire sequence $(\mathrm{B} 2-\mathrm{C} 1-\mathrm{C} 2)$ is intruded by sand dykes originating from the lower layer B1. This sediment package is further overlain by a heavy mineral reach marine sand (layer D) with liquefactions long axes inclined southward as a result of forceful long-shore drift. The profile ends up with coarse-grained, poorly sorted sand including angular clasts of terrigenous outwash deposits indicating return of distal inundations. Intense deformation (liquefaction) is restricted to the heavy mineral-rich marine and the intermixed sands (layers B2 and D), whereas the terrigenous sand layers show scoured bases with oscillatory and pebbly tops. The presence of complex load structures injecting into the underlying layers, the top-truncated sand dykes, macro-thrust faults, scouring, and inclusion of coral fragments can explain it as a record of tsunami in the west coast. Occurrence of un-decayed consumer plastic material within the deformed layers suggests it as one of the most recent tsunami events (i.e., 2004 IOT), the only reported event after 1945 in the west coast. Alternative marine and terrigenous sands are characteristic of tsunami run-up and backwash deposits, while the dimensions of SSDs may be related to the $<2$ m magnitude (height) of the 2004 IOT at Dive Agar.

Keywords: Indian Ocean Tsunami, Tsunamite 


\section{Introduction}

Tsunamies have significant depositional and erosional geomorphic impacts on the coastal landscapes. A wide variety of landforms produced by tsunami have been noted by many scientists [Morton et al., 2007, Kortekass and Dawson 2007, Buynevich 2005, Scheffers and Kelletat 2003]. These landforms provide important information on the energy and dynamics of tsunami waves including the height, velocity, competence and erosive energy, beside the evidence of past tsunami. However they are not studied in the comprehensive way, especially along the west coast of India, probably because of limited tsunami events, [Rajamanickam and Prithviraj 2006 and Pendse 1945] that affected the west coast of India. Whereas the frontal coastlines of Peninsular India such as East coast of India has received the direct and larger magnitude hit of the tsunami, the distal and rearer coastline of the west coast suffered a variable intensity influenced by the coastal geomorphological access (e.g., Dawson, 1994, Goff et al; 2004, 2001, Dawson and Shi, 2000). A search for the tsunami related deposits (called 'tsunamites' Shanmugam, 2006) in the west coast is thus warranted to inter-relate the style of tsunami inundation with beach morphology. In this context we hunted for the tsunamite like features (e.g.Rajendran et.al- 2006, Shanmugam, 2006, Goff et al., 2004, 2001, Dawson and Stewart, 2007, Dawson 1994, Nelson et al; 1996) in the northern west coast of Maharashtra, and this paper reports a set of PCD's from the Dive Agar beach (Konkan coast) that can be related to the recent tsunami event.

\section{Tsunamites}

Large earthquakes (usually $M \geq 6$ ) can produce a wide variety of syndepostional (Rajendran etal. 2004, Kumar etal. 2001) structures caused by liquefaction of unconsolidated sediments (Obermeier, 1996) and by lateral movements, such as slumps and landslides (Seilacher, 1984). Rapid cyclic shearing of unconsolidated sediments by earthquake waves and tsunamis can lead to compaction and a concomitant increase in pore pressure, causing liquefaction of the sediments (Obermeier and Pond, 1998). This phenomenon is most common in sand-sized material (Valera et al., 1994) and can result in the formation of clastic dikes in an overlying nonliquefied layer that is fractured by the elevated fluid pressure in the liquefied sand, by surface oscillations, or by lateral spreading, or the overlying layer may contain preexisting fractures (Obermeier, 1996; Obermeier and Pond, 1998). Loosely consolidated and water saturated sands and silts with low cohesion are the suitable sediments to record the seismic and tsunami related phenomena (Dzulynski 1966; Mills, 1983). The coastal areas are thus best suited for such records 
provided they are preserved well in the context of the long term coastal dynamics. Because of favorable sediment conditions in beach environments following an excess of pore pressure in water-saturated environments, the sediments may immediately loose the cohesion and liquefy meeting the basic textural requirements for plastic load deformation and plastic flow. We discovered such notable features at Dive Agar beach near Srivardhan $\left(18^{0} 10^{\prime} 23^{\prime \prime} \mathrm{N}, 72^{0} 59^{\prime} 12^{\prime \prime} \mathrm{E}\right.$ with aerial distance of $\sim 2770 \mathrm{Km}$ from the epicenter) that are discussed in this paper.

\section{The Historical records of Tsunami}

In the last 300 years, the Indian Ocean region,13 tsunamis are reported in the Indian Ocean (Table 1), and 3 of them occurred in Andaman and Nicobar region for which the details of location of epicentre, death/damage caused etc are poorly known (DOD, 2005). The 1945 tsunami had a maximum run-up height of $13 \mathrm{~m}$ in Pakistan and resulted in death of 4000 people following an earthquake of magnitude 8.2 in the Arabian Sea. Overall, the run-up levels varied from 1 to $13 \mathrm{~m}$. In 1977, one of the strongest earthquakes of magnitude Ms 8.1 struck west of the Sumba Island in Indonesia, but there were no reports of casualties in India due to this tsunami (DOD, 2005). Apart from those listed in Table 1, there may be additional destructive tsunamis in the Indian Ocean that have not been properly documented. For example villagers of Simeulue Island, off the coast of Sumatra, speak of a destructive tsunami in 1907 that had killed thousands of people (Op.cit).

\section{Geology}

The west coast of India is pronounced by the Western Ghats that are residual escarpments initially developed by the rifting off of Madagascar and Seychelles microcontinents (Gunnel and Radhakrishna, 2001) The coast is flanked by narrow zone of onshore Tertiary sedimentary basin in the southern apart developed during graban formation over the entire width of the continental shelf. The sediment distribution pattern may be dived into two major types: a) Contribution from rivers forming the near shore facies upto $50-60 \mathrm{~m}$ water depth consisting of silty clays and b) Quartz reach sand beyond $60 \mathrm{~m}$ depth.

Physiographically, the western coastal region can be divided into i) the $25-40 \mathrm{~km}$ zone of Western Ghats rising steeply to an altitude of $1200 \mathrm{~m}$ as straight escarpment, ii) The $20-30 \mathrm{~km}$ wide narrow coastal strip pf $\sim 30 \mathrm{~m}$ height drained by over 41 fast flowing rivers and iii) The narrow 
continental shelf with an average depth of 29 fathoms. The Western Ghats receive $\sim 3000 \mathrm{~mm}$ annual rainfall. The beaches along the western coast are about $3-4 \mathrm{~m}$ high. Bathymetry indicates an enlarging continental shelf towards the Gujrat coast (Fig. 1) In the Deccan basalt province of the Konkan Coast of Maharashtra the drainage divide and the escarpments coincides and there is little variation in the scarp sinuosity as well as width of the coastal plains (Fig.1, Kale and Shejwalkar, 2007, Harbour and Gunnel., 2007). The sandy beaches in this area vary in length from $1-5 \mathrm{~km}$ and width $20-200 \mathrm{~m}$. A vareity of landforms both suggestive of submergence and emergence are quite common in the Konkan Coast by the development of features such as offshore islands, estuaries, headlands associated with cliffs, sandbars, sand spits, and mangrove swamps, littoral terraces, uplifted abrasion platforms and the rocky beaches. (Fig. 1a). The Dive Agar beach (Fig. 3) comprises of a narrow (20 to 125m) sandy beach followed by an uplifted abrasion platform $(400-500 \mathrm{~m})$ and a large mudflat area. The northern and southern boundary is marked by the estuarine river creeks.

\section{Records of the 2004 IOT at Dive Agar}

The December 2004 IOT although reported no damages at Dive Agar, the local eye witness quoted its landward inundation crossing the bridge (shown in fig. 4a) and till the base of the upland hills, (the distance measuring measures to about $1.5 \mathrm{~km}$ ) It is likely that the tsunami deposits have been largely reworked during the last 3 / 4 seasons after the event, when the estuary flooded during the monsoon. Also the local people are mining the sand and gravels at large for building material destroying most of the profiles. With the general assessment of the geomorphic setup in the area we planned a trench perpendicular to the landward run-up direction [NNW- SSE] (see fig. 4b) exposing a flat sand-spit near and parallel to the shoreline. The trench opened for about $30 \mathrm{~m} \mathrm{N-S}$, where the clear PCD zone is observed in the first $18 \mathrm{~m}$, while its southern extension is mainly collapsed/reworked and then merges into the rocky beach for about $35 \mathrm{~m}$. There is a tree line gap in this part of the beach otherwise the stabilized dune surfaces are supported by dense vegetation (Fig. 4c).

Figure 5a shows part of the trench along with a litholog showing the layers of individual sediment packages. The basal layer $\mathrm{A}$ is the well fine sorted beach sand with alternate grading of grain size. This layer varies from $20-40 \mathrm{~cm}$ through the trench as a result of scouring by the overlying Layer B1. Layer B1 is a massive course grained, poorly sorted sand with occasional disorganized pebbles $(0.5$ $-3 \mathrm{~cm})$. As the tsunami wave approached the coast, seabed sediments are suspended and a basal erosion surface is created (see the base for Layer B in fig. 5b). The layer Blappear to be deposited at the 
instance when the landwards current related to shoreward direction as the velocity passed through zero during this reversal, quickly depositing the sediments. The Layer B2 shows high adulatory lower margins and sharp straight truncated upper boundary. We named the Layer as B1 and B2 because beyond $18 \mathrm{~m}$ they are unrecognizable as seprate layers with naked eye. Layer B1 is scooped by layer B2 of coarser, poorly sorted sand with angular clasts and disorganized pebbles. This indicates the first turbulent backwash deposits as a result of the first tsunami surge (S-1) containing the mix terrigenous and marine (beach and shelf) sediments of the Layer B2 (note: Layer B2 is darker in contrast to B1 due to heavy mineral content, See fig. 5 ). The layer B2 is sharply cut with straight margin (unlike its undulatory lower margin) by the overlying Layer $\mathrm{C}$ indicating the erosional boundary. We thus infer the sediment package of wave of the tsunami denoted as $\mathrm{S}-1$. The layer $\mathrm{C}$ is again the landward run-up of the second wave of tsunami (denoted as $\mathrm{S}-2$ ) instantaneously depositing the Layer $\mathrm{C}$ during the reversal of current. In the similar manner (as the layer B1), the layer $\mathrm{C}$ is also intensely scooped by the grey sand layer of D. The grey color, apart from the heavy mineral content infer less terrigenous mixing with marine sediment laden water of the surge S-2. The higher intensity of deformation in the entire this layer of D (Fig. 5 - 6) indicates higher terbulance or intensity of the second serge( S-2)relative to S -1. The upper boundary of layer $\mathrm{D}$ with layer $\mathrm{E}$ is also undulatory. The Layer $\mathrm{E}$ is the coarsest sand amongst all the layers with high angularity and increased frequency of the angular lateritic pebbles of 1 to $5 \mathrm{~cm}$, probably indicate the backwash from the distal inundations and the last deposit of the tsunami in this region. Occurrence of this style of sedimentation is indicative of the systematics and mechanism of the tsunamites in the region. The undulatory margins of the PCD layers is due to the higher specific gravity of the marine sediments as well as large eroding capacity of the surge. The layers D and E particularly contains the pieces of undecayed TV cables, plastic ropes and bags, that are fresh enough not to be older than 5 years (Fig. 5a and d). This helped us to relate the tsunami deposist as the most recent one, i e., the 2004 IOT.

Majority of the PCD deposits at Dive agar trench appears to be developed by a systematic of scouring and deposition followed by liquifaction. During the backwash, the scouring developed an undulatory base which was immediately filled up by the water saturated heavy mineral reach high gravity sediment load in $\mathrm{Z}$ direction (see the axis direction in fig. $5 \mathrm{c}$ ). This sediment load later on subjected to overpressure by the overlying layer leading to liquefaction injected by hydroplastic flow developing (stretching) the structures in X-Y direction (see fig 5-6). Also it is to be noted that only the grey and brownish grey sand layer are highly liquified while the brown layer mostly acted as cushion. 
This suggests two possibilities: a) The grey sand coming as sediment load of tsunami wave was highly water saturated relative to the brown sand coming as terrigenous outwash, b) The terrigenous sand is clay/silt rich which might have acted as cohesive force to deformation.

At few places the grey sand of D- layer shows ductile thrusts and normal faults (fig 6a and $b$ ). At figure $6 \mathrm{c}$ there is small sand dyke from the grey sand layer of D intruding into layer E. At the southern and terminal part of trench it mostly shows slump structure (fig. 6e). We further opened up a small trench in the E-W direction, i.e., parallel to the tsunami runup direction in a dune near the main trench (fig. 7a). Again there are two deformed layers $7 \mathrm{~b}$ but with a different style of deformation to the main trench. The lower layer mostly shows disrupted convolutions while the upper layer can be equated to sand blows producing a flower structure (se fig $7 \mathrm{~b}$ ). However in absence of dating we can not correlate any of these layers to the main trench, wanting to further studies based on TL/OSL dating. At about $600 \mathrm{~m}$ from the main trench parallel northward, we find another major deformation layer with spectacularly disrupted beds (fig 7b). However again this could not be correlated to the main trench,

questioning whether it is another paleotsunami record (Table 1) independent of the 2004 IOT. Away from the beach about $1 \mathrm{~km}$ landward in still older stabilized dunes we find a set of disrupted convolutions and shear faults. These deformations are surely related to tsunami other than 2004 IOT, as they are occurring in some of the oldest stabilized dunes in the area, where the 2004 IOT did not affect.

\section{Conclusion}

The deposits of the 2004 IOT at Dive Agar are characteristic of sedimentary package of stwo waves of tsunami arrival. A numerical model for the global propagation of the 2004 IOT (Titov et al. 2005) represents two packets of tsunami waves, the first comprising relatively small amplitude, faster waves followed by the second packet of typically higher amplitude and slower waves. Further studies and more records are warranted to relate the tsunamites from the west coast to any such numerical model to understand the mechanism of tsunami inundation and deposition.

\section{Acknowledgements}

The authors are grateful to the Head, Department of Geology, University of Pune and Director, National Institute of Oceanography, Goa for providing all the facilities and the encouragements. The work in this project was funded under the UGC scheme BCUD/285/2006 to DCM. SJS is also thankful to Director, Wadia Institute of Himalayan Geology for the lien extended to him. 


\section{References:}

Banerjee P, F.F. Pollitz, B. Nagarajan, R. Bürgmann, Coseismic slip distributions of the 26 December 2004 Sumatra-Andaman and 28 March 2005 Nias earthquakes from GPS static offsets, Bull. Seism. Soc. Am. 97, doi: 10.1785/0120050609(2007) 86-102.

Buynevich I. V. [2005] Sediments shed light on past coastal events, Geotimes [November 05] p. 1-3

Dawson A. G. and Shi, S. (2001) Tsunami deposits, Pure and applied Geophysics V. 157. 187 -897

Dawson, A. G., Stewart, I. 2007. Tsunami deposits in the geological record Sedimentary Geology. 200, 166-183.

Dawson, A.G., 1994. Geomorphological processes associated with tsunami runup and backwash. Geomorphology 10, 83-94.

DOD, 2005. Department of Ocean Development, Chennai, 1-45.

Dzulynski, S., 1966. Sedimentary structures resulting from convection-like pattern of motion. Rocz. Pol. Tow. Geol. 36,3 -21.

Goff, J., Chagué-Goff, C., Nichol, S., 2001. Palaeotsunami deposits: a New Zealand perspective. Sedimentary Geology 143, 1-6.

Goff, J., McFadgen, B. G., Chague, C. 2004. Sedimentary differences between the 2002 Easter storm and the 15th-century Okoropunga tsunami, southeastern North Island, New Zealand. Marine Geology, $204,235-250$.

Gunnel, Y. and Rashakrishna, B. P. 2001. Sahyadri, the great escarpment of the Indian Subcontinent. Patterns of landscape development in the Western Ghats. Mem. Geol. Soc. India. 47, 1054p.

Harbor, D. and Gunnel, Y. 2007. Along-strike escarpment heterogeneity of the Western Ghats: A synthesis of drainage and topography using digital morphometric tools. Jour. Geol. Soc. India, v.70, 411-426.

Kale, V. S. and Shejwalkar, N. 2007. Western Ghat escarpment evolution in the Deccan basalt province: Geomorphic observations based on DEM analysis. Jour. Geol. Soc. India, v.70, pp. 459-473.

Kortekaas S. and Dawson A. G. [2007] Distinguishing tsunami and strom deposits: An example from Martinhal, SW Portugal. Sedimentory Geology V.200 p. 208- 221

Kumar, S., Wesnousky, S. G., Rockwell, T. K., Ragona, D., Thakur, V.C., Seitz, G. G. (2001). Earthquake Recurrence and Rupture Dynamics of Himalayan Frontal Thrust, India, Science, 294/5550, $2328-2331$.

Marine Geology, v. 55, p. 1-12.

Mills, P.C., 1983. Genesis and diagnostic value of soft sediment deformation structures-a review. Sediment. Geol. 35, 83-104. 
Morton Robert A, Gelfenbaum G., and Jaffer bruce E [2007] Physical Criteria for distinguishing sandy Tsunami and storm deposit using modern example. Sedimentory Geology. V. 200, p. 184- 207

Nelson, A. R., Shennan, I., and Long, A. J. 1996. Identifying Coseismic Subsidence in Tidal-wetland Stratigraphic Sequences at the Cascadia Subduction Zone of Western North America, J. Geophys. Res. 101 (B3), 6115-6135.

Obermeier, S.F., 1996, Use of liquefaction-induced features for paleoseismic analysis. Engineering Geology, v. 44, p. 1-76.

Obermeier, S.F., and Pond, E.C., 1998, Issues in using liquefaction features for paleoseismic analysis: U.S. Geological Survey Open-File Report 98-28, 38 p.

Pendse C. G. (1948) The Makram Earthquake of 28 Nov 1945. Indain, Meteorol Dept., Science Notes $10,141-145$

Rajackam G. V. and Prithviraj M. (2006) Great Indian Ocean tsunami: Indian Perspective in $26^{\text {th }}$ Dec. 2004 Tsunami [causes, effects, remedial measures, pre and post tsunami disaster management] a geoscientific perspective and Editor - G. V. Rajamanickam, B. R. Subramaniyam

Rajendran, C. P., Rajendran, K., Machado, T., Satyamurthy, T., Aravazhi, P., Jaiswal, M. 2006. Evidence of ancient sea surges at the Mamallapuram coast of India and implications for previous Indian Ocean tsunami events.Current science, v. 91/9, 1242-1247.

Rajendran, C.P., Rajendran, K., Duarah, B.P., Baruah, S. and Earnest, A. 2004. Interpreting the style of faulting and paleoseismicity associated with the 1897 Shillong, northeast India, earthquake: Implications for regional tectonism. Tectonics, 23, 4009, doi 1029/2003/TC001605, 2004

Scheffers A, and Kelletat D [2003] Sedimentologic and geolorphic tsunami imprints world wide- a review. Earth Science Reviews V. 63 p. 88-92

Seilacher, A., 1984, Sedimentary structures tentatively attributed to seismic events:

Shanmugam, G., 2006. The Tsunamite Problem. Journal of Sedimentary Research; 76/5; 718-730.

Titov, V., Rabinovich, A. B., Mofjeld, H. O., Thomson, R. E., González, F. I., 2005. The Global Reach of the 26 December 2004 Sumatra Tsunami. Science Vol. 309. no. 5743, pp. $2045-2048$ 


\section{Figure Captions}

Figure 1: (A) Bathymetric map showing the continental shelf off the west coast of India. Source: Atlas of Oceanic Interval Solitary Waves 2002, Global Ocean Association p221 (B) A generalized profile of the west Coast of India.

Figure 2: Drainage map of Western Deccan Basalt Province ( after Kale and Shajwalkar 2007)

Figure 3: A generalized geomorphological map of Dive Agar beach area (Thigale etal.1998)

Thigale S.S, Pawar N.J., Meshram D.C (1998) Hydrogeology and geochemical studies on saline and fresh water interaction in the coastal aquifers, Maharashtra Project Reported to DST, New Delhi, No. $\mathrm{ES} / 023 / 198 / 94)$

Figure 4: An overview of the broad geomorphic setup at Dive Agar beach indicating the area of tsunami inundation (a), the direction of the tsunami run-up and the location of trench (b) and the tsunami appears to have entered (c)

Figure 5: A bround view of the trench opened along with the litholog and (b) to (e) indicating the closeups of the identified packages related to various episodes of the tsunami events-(detail given in the text). Figure 6: Away from the main trench, the occurrence of deformation features perpendicular to the main trench (a) and (b). The deformation features are also observed at about 600m away from the main trench within the beach in northward direction (c) and over an older stabilizes Dun in the area (d) probably suggests the older tsunami events. 


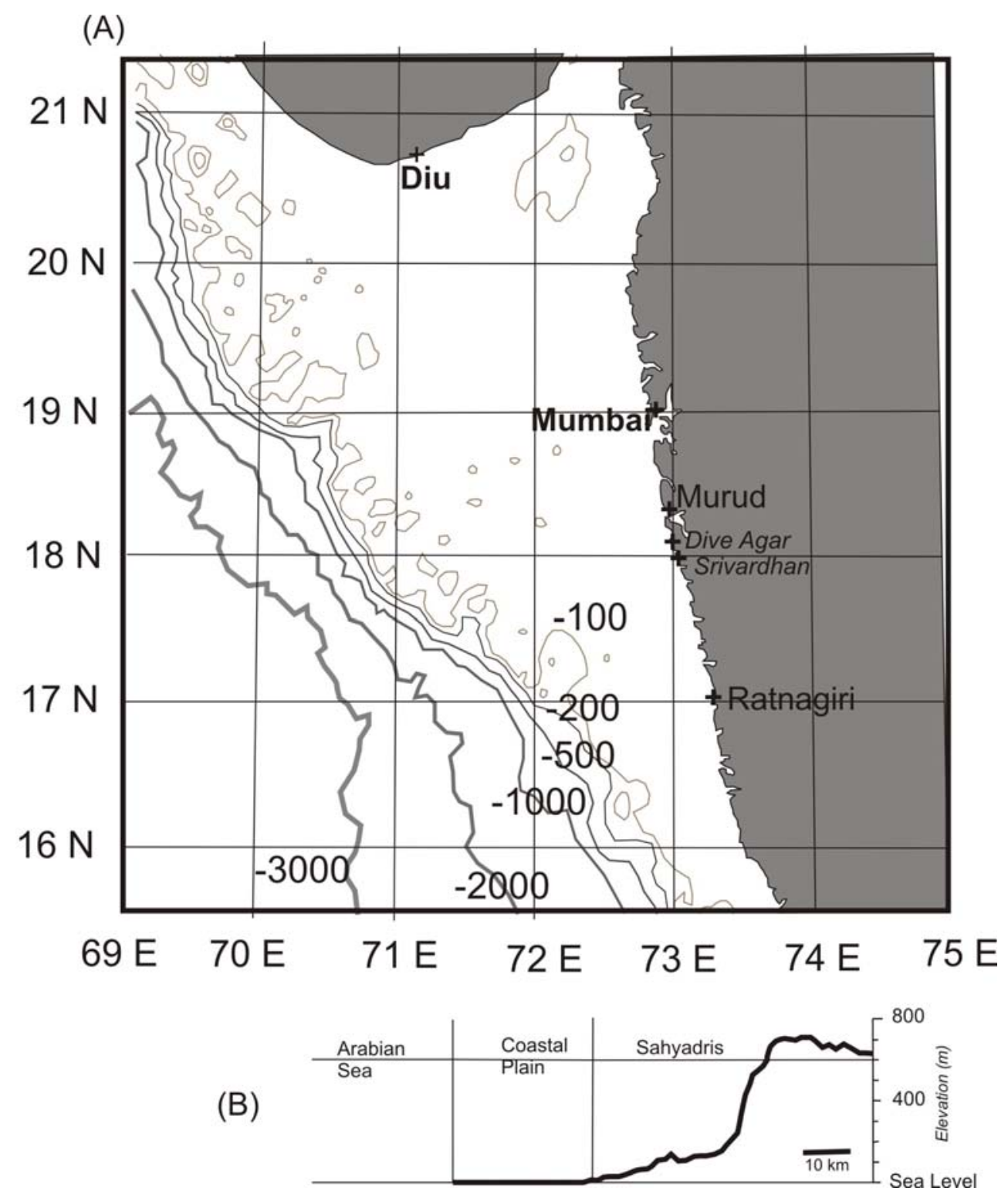

Figure 1 


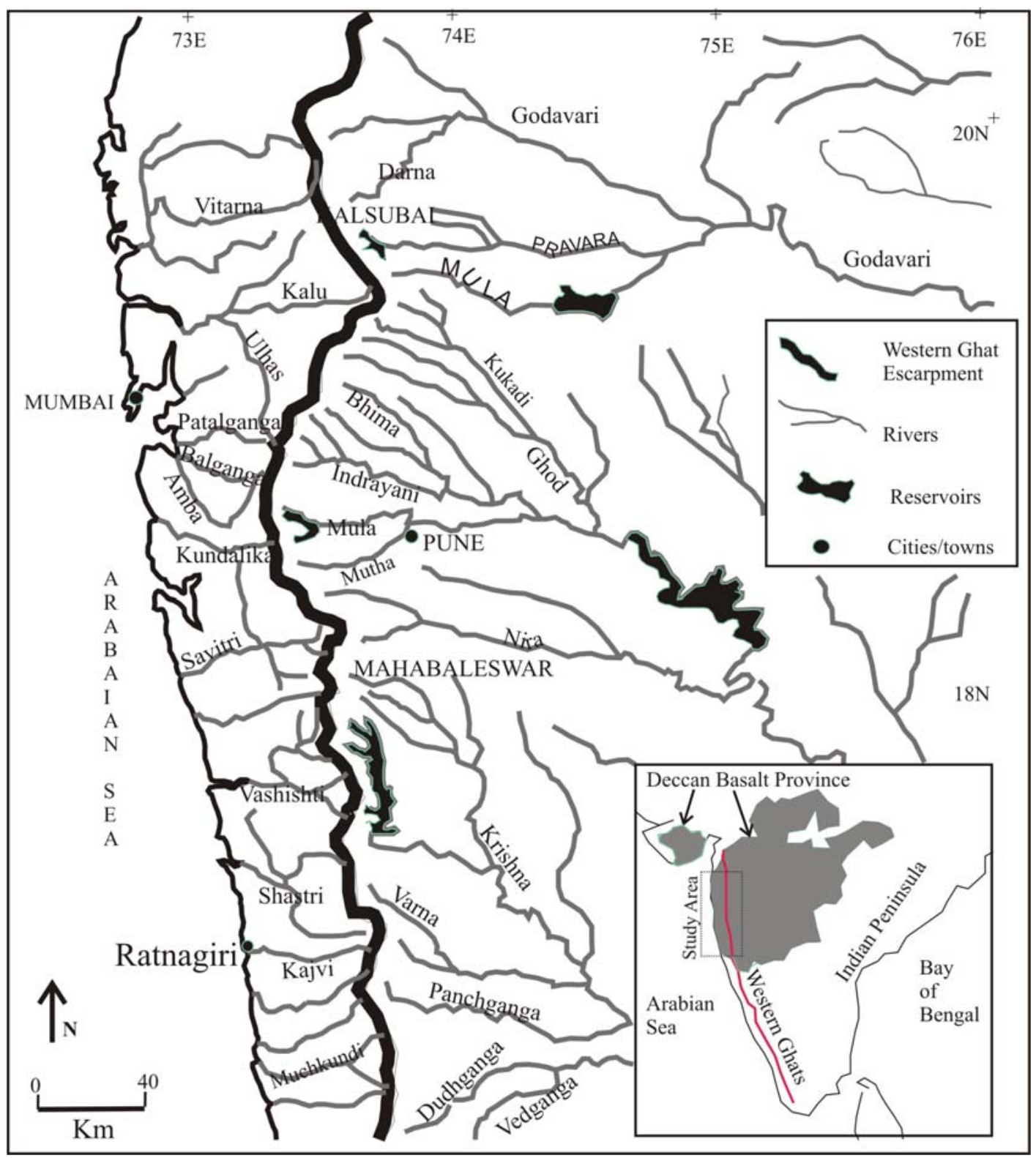

Figure 2 


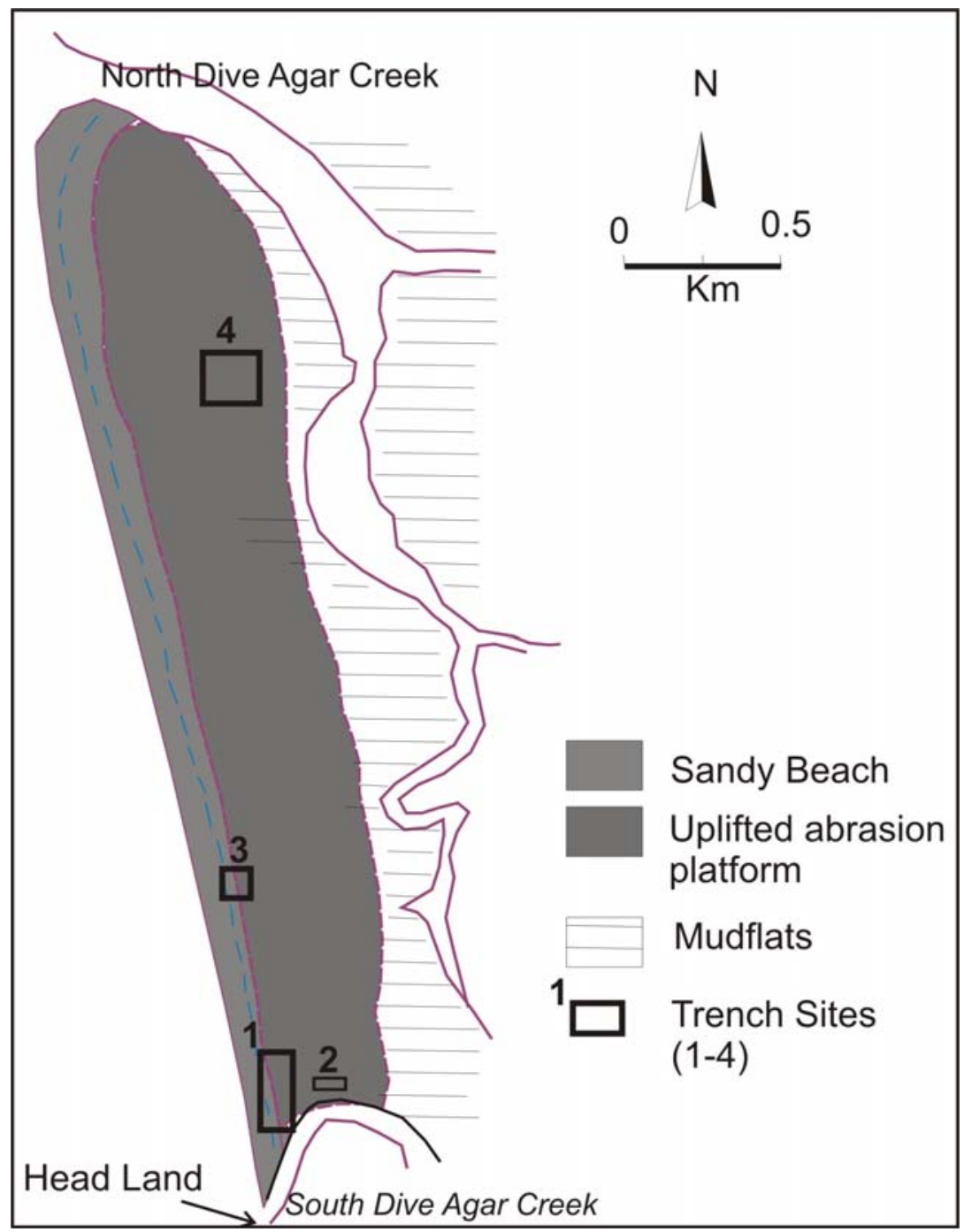

Figure 3 


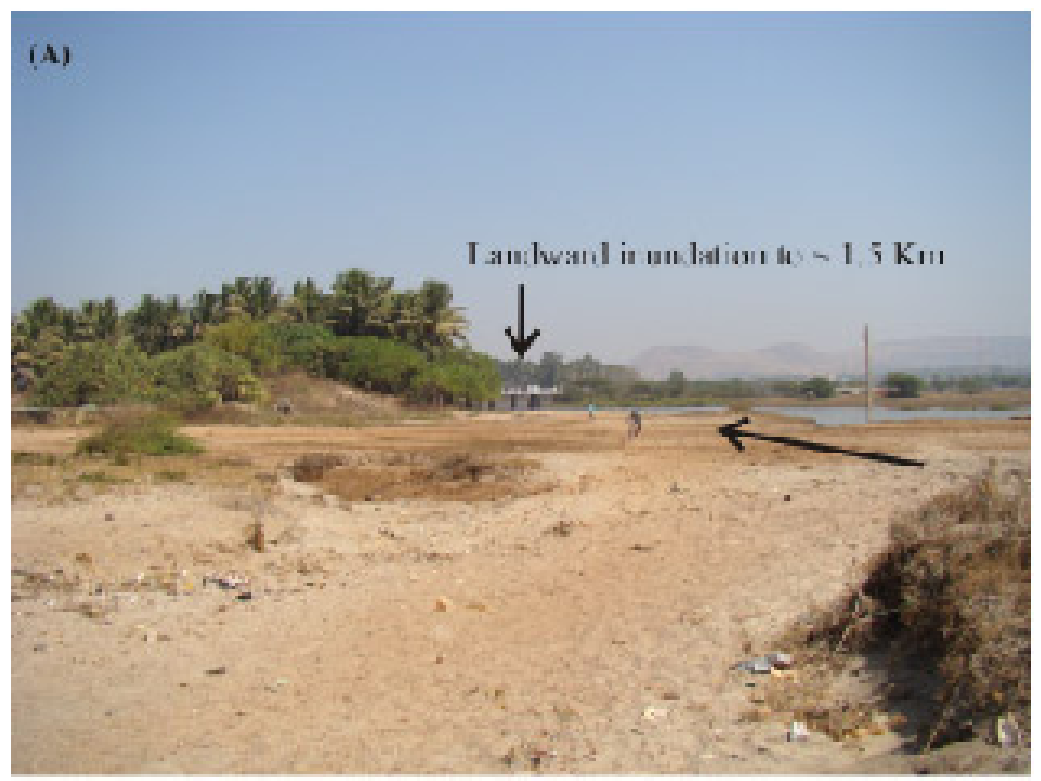

(B)

Figure 4
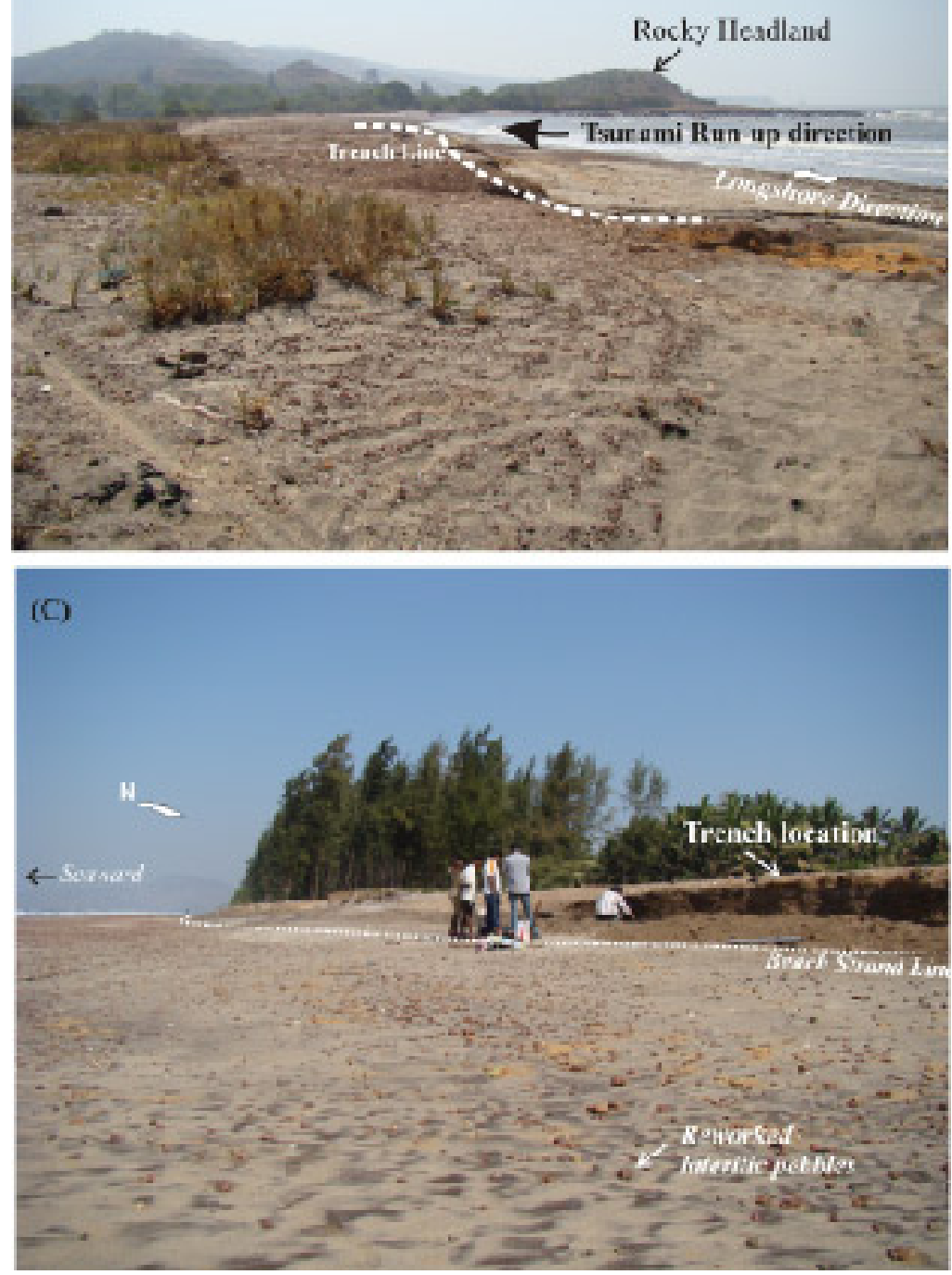


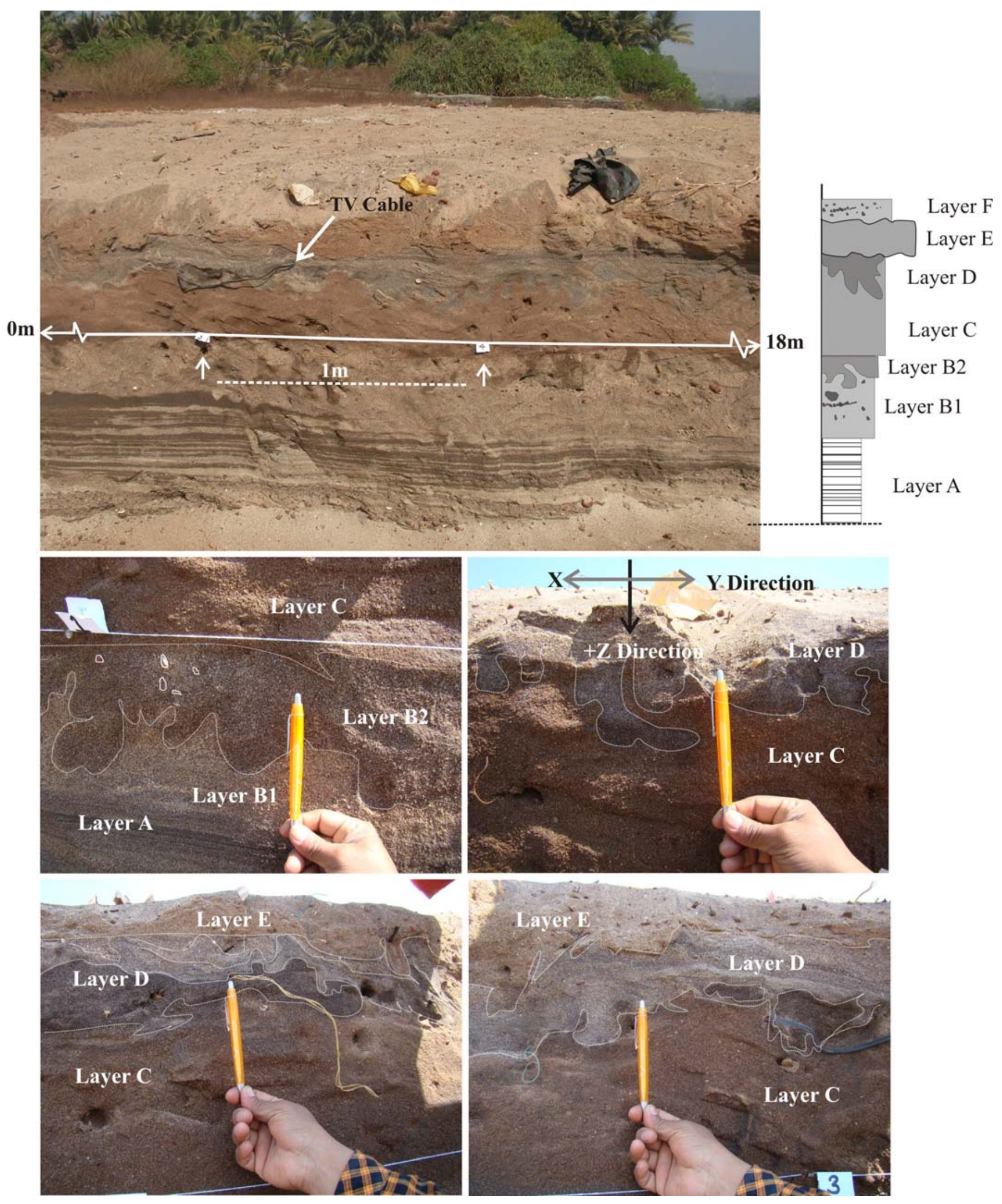

Figure 5 

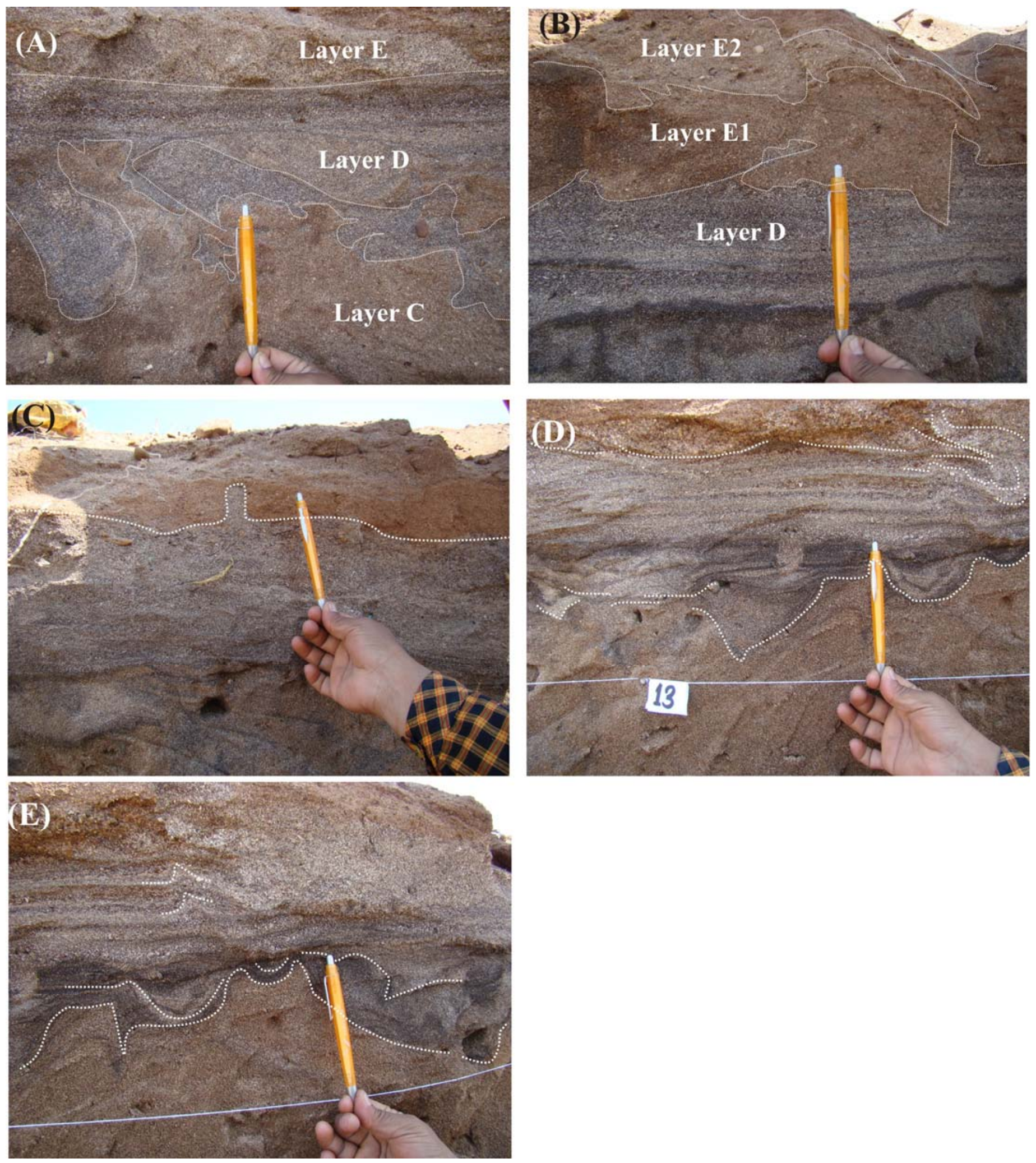

Figure 6 